I am delighted with it. Will anyone say-and there are abundant witnesses--that it is not a rapid and complete proceeding in my hands? How could that be possible if my aspirator is so defective ?

And now I have ouly to congratulate Professor Bigelow on his present search for "simplicity." He well knows that I regard his suggestion to remove the stnne at one sitting as a great advance. But his first instruments were a return to the time of Heurteloup! After years of patient experience, the mechanism of both lithotrite and evacuator had become marvellously simple and efficient. This simplicity be disturbed, disastrously, for a time; exhibiting elaborate and costly apparatus at the Congress here in 1881, wholly useless to the practical lithotritist. He could not see that not one new instrument was required to carry out his excellent idea. As we were to attack larger stones, we wanted larger and stronger instruments--that was all. Clover's bottle, a little modified perhaps (as I suggested last January in THE LANCET) is as good as, if not better than, any, and $T$ still often use it. ${ }^{1}$ Only make it larger than before, and attach a larger evacuating catheter, when you want a larger, not otherwise. All the perforated tubes and strainers get so blocked with débris (as I found long since) in the human bladder-not with coal in water-as to be practically useless there.

I am heartily sorry to have been compelled to reply in a spirit of criticism, but the statements and the mode of proceeding referred to a bove rendered it impossible for me longer to remain silent.

Wimpole-street, W., Jan. 1883. am, Sir, yours ohediently,

HENRY THOMPSON,

\section{"CASE OF FEIGNED SKIN DISEASE."}

\section{To the Editor of THE LANCET.}

Sir,-The case of factitious skin disease, put on record by Dr. Colcott Fox, reminds me of one that came under my observation some years ago when I had charge of the dermatologic al clinique at St. Thomas's. A girl of seventeen, a maid of all work, came before me one winter-that is to say, at a time when hands and arms which are exposed to air and wet are apt to get chapped-with considerable chapping and soreness of all these purts. She professed n't to consult me about this bowever, but about a considerable number of holes in the skin of her forearms, which she said were produced by carrying pails of water and other heavy things up and down stairs. She stated that when thus engaged she would frequently feel something give way in her arm, and that, on looking, she always discovered a newly formed hole. At the moment I was inclined to think that the wounds might really be due to the sudden extension in depth aud length of some of the pre-existing chaps, determined by the stretching to which the skin had been subjected. A little examination, however, satisfied me that the holes were of artificial production. They were all of exactly the same character; their direction was horizontal or nearly so ; they were oval, or rather egg.shaped, with the pointed end always in the eame direction; they were between $\frac{1}{4}$ and $\frac{1}{3}$ inch in length ; their edges were smooth and verti.d, and they looked as though they had been made with a punch; there was no surrounding thickening or inflammation, and their floor was formed of the healthy subcutaneous connective tissue. I concluded she had snipped out pieces uf the skin with scissors. I explained my views to my class, out of the girl's hearing ; and one of them left the room and presently returned with two or three wounds in his arm, which were the exact counterparts of the girl's. He had made them with scissors; and added that no pain attended their production. I said nothing to the gill on ber first visit; but on the second, eharged her with deceit, and threatened to inform her mistress. I need scarcely say I did not see her again.

I remain, Sir, yours truly,

Old Burlington-street, $J_{\mathrm{an}}$. 5th, 1883.

\section{J. S. BRISTOWE,}

1 Professor Bigelow persists in repeating that the size of the evacuating sound in Cover's instrument is No. 21. I do not dount that he bas seen one of that size, but there was no limit in that matter formerly, as there is none now; the operator used any size he thought proper. One now at iny side, which I have had upwards of fifteen years, is No. 23. With Clover's apparatus 1 reinoved sctres of stones before the one sitting system was proposed. I am glad to see that Mr. Brkeloy Hill employed Clover's bottle recently (vide THE LANCET, Jan. Ijeb); I really do not think he will find one much better.

\section{"PICRIC ACID AND SUGAR TESTING."}

\section{To the Editor of ThE LANCET.}

Sin,-Strange, almost incomprehensible, as it may seem, I need not go farther than Dr. Johnson and his son's admis sions to substantiate my position in this controversy, which has now resolved itself in to the simple question of whether or not a sulphide is produced on boiling albumen with a solution of potash.

To be quite sure that there is no misunderstanding about what has been stated, let us start with the following quota. tions. Dr. Johnson says that his son "demonstrates and explains the fact that while a lead sulphide is formed by boiling albuminous urine with liquor potassæ mixed with lead, no alkaline sulphide is formed when the same urine is boiled with pure liquor potassce." The son, after mentioning that it is stated and accepted as a fact in chemical text-books and to be found in so many words in Watts' Dictionary that albumen gives rise to an alkaline sulphide when boiled with a solution of a caustic alkali, says that he was surprised to find that it "produced no trace of sulphide, even after boiling for half an hour with a strong solution of potash; the solution thus obtained gave no dark colour or precipitate with a solution of acetate of lead." Further on he states that " if the lead solution was added to the albumen and potash before boiling, and heat afterwards applied, an abundance of lead sulphide was produced. "The fact is," he continues, "that a sulphide can be produced only by boiling an alkaline solution of albumen (made in the cold) with a metallic solution, such as one of lead or copper."

Here we have it stated in unequivocal language that a sulphide is not formed on boiling albumen with potash. This is the stand-point of Dr. Johnson and his son. Now, what does the son say in his communication contained in your last week's issue? "With the object of allowing every possible chance for the production of an alkaline sulphide by the action of caustic potash upon solution of albumen at the boiling temperature, I boiled the alkaline mixture for 'half an hour,' as Dr. Pavy has correctly quoted me. The result was that no trace of sulphide was producted, as I have already (equally correctly) stated. Dr. Pavy, on the other hand, speaks triamphantly of an abundant production of sulphide observed on adding a solution of lead to one of albumen and potash which had previously been boiled for 'fully five minutes.' I have repeated this experiment of Dr. Pavy's, and can corroborate his statement, that 'it does not signify whether the lead solution be added before or after the boiling,' when the ebullition has been continued for so short a time, and when the quantity of albumen present is so large as it was in Dr. Pavy's experiment."

The question, then, resolves itself into the issue being depeodent upon the length of time the boiling with potash is carried on. It is admitted by Mr. Sillingfleet Johnson that after boiling for five minutes the evidence of the formation of sulphide is obtainable, and stated that after boiling for half an hour no sulphide may be discoverable. To this latter statement $I$ assent, and we are thus brought to an agreement upon facts.

Agreeing then upon the facts, what inference is to be drawn from sulphide being discoverable at the end of five minutes, and not at the end of half an hour? Obviously that during the process of boiling it undergoes destruction. If it is admitted to be there at the end of five minutes, how is it conceivable that anyone should argue that it is not formed because it is not found at the end of half an hour? It is useless to waste time and words with those who argue upon such grounds.

I have said that $I$ assented to the statement that no sulphide may be discoverable at the end of half an hour, and I have to say further that the gradual loss of sulphide may be watched. For about ten minutes or a quarter of an hour the quantity of sulphide present goes on increasing, as shown bv testing the product with lead solution from time to time, bot after this it declines, and sometimes when the boiling has been continued for half an hom the sulphide is found to have disappeared, but more often a longer period of boiling than this is required. No wonder that the careful and elaborate experiments of the son, which have bfen so repeatedly expatiated upon by the father in your columns, failed to reveal the presence of a sulphide. The observer was scarching for that which be had previously destroyed.

Mr. Strllingfleet Johnson may learn, if he will scrsilt his 
chemical works, that looking at the properties of alkaline sulphides there is nothing inconsistent in what I have stated about a destruction occurring. The alkaline sulphides, we are directly told, have a tendency under the influence of air and moisture to become oxidised and converted, first, into a byposulphite, then a sulphite, and ultimately a sulphate.

I cannot allow the last few words of the quotation given above from $\mathrm{Mr}$. Stillingfleet Johnson's communication to pass without something being said upon them. He can corroborate my statement, the text runs, about the formation of a sulphide, "when the ebullition has been continued for so short a time, and when the quantity of albumen present is so large as it was in Dr. Pavy's experiment." When the quantity of albumen present is so large! What influence can quantity of albumen have if no sulphide is producible from it ? Such an expression, constituting as it does so glaring an offence against the first principles of reasoning, would not be looked for from a first year's medical student, or even, I wild say, an adranced school-boy ; but it comes from Dr. Johnson's son, who, Dr. Johnson has taken care in the course of this controversy your readers should be informed, is the Junior Demonstrator of Chemistry at King's College.

Having brought the discussion to this point I will now quote, and leave to the consideration of your readers, the opening paragraph of Dr. Johnson's letter of last week. "Your correspondent, Dr. Pavy, in this matter of sugar testing has evidently resolved to place himself hopelessly in the wrong. He ignores the elementary principle in practical chemistry that even a slight modification of an experiment may lead to results entirely different, and apparently contradictory, and with a light heart he endeavours to refute the conclusions derived from carefully conducted and accurately recorded experiments by a hasty proceeding, undeserving the name of an experiment [this experment, which Dr. Johnson speaks so disparagingly of, happens to constitute the rock upon which he and his son have struck and foundered], unless, indeed, it be an experiment upon the patience and credulity of your readers. The proof of this serious charge against Dr. Pavy as a scientific observer and a controversialist will be mainly found in my son's letter, which you will doubtless publish with this."

These are, indeed, strong words, but I fully admit that I merit their application to me if I have erred as Dr. Johnson states, and, on the other hand, if I do not misjudge the pro fession, I think I may conclude that they will recoil with greatly increased force upon the one who has used them if his conclusions, instead of mine, are proved to be fallacious.

There is an imputation conveyed in the following assertion of Dr. Johnson which I cannot allow to pass unnoticed. "From the fifth paragraph of Dr. Payy's letter it is evident that he has repeated the experiment of prolonged boiling normal urine with potash, described by my son in your impression of December 16th. He has not found that an alkaline sulphide resulted from this experiment, as he anticipated would be the case, though he has not the candour to acknowledge the fact. He says, whatever might have been the issue of this discussion about the formation of a sulphide, the fact stands that healthy urine gives a certain degree of reaction with the picric acid and potash test, and this, independently of the trace of sugar which healthy urine contains, for it is obtainable after boiling the urine with caustic potash, a treatment which leads to the destruction of the sugar. This statement contains that mixture of truth and error which appears to characterise all Dr. Pavy's communic ations on this subject."

I utterly repudiate the suggestion that is here made, and emphatically state that up to the present moment I bave not performed the experiment referred to. Indeed, notwithstanding the kind advice given me by Mr. Stillingfleet Johnson in the first paragraph of his last communication about the mode of experimenting to adopt. I have not been tempted to follow his course of procedure. I prefer sim plicity and accurasy to complexity and fallacy.

There is so much confusion in Mr. Stillinglleet Johnson's writing, that he contradicts in the latter part of his com munication (in your last issue) what he has stated at the beginning; but what he says about pure albumen behaving different $y$ from white of egg is absolutely contrary to fact and I demur to the validity of his statement that, "the idea that an alkalive sulphide may be at first formed and afterwards derompost by proluneed ebullition, is negatived by the fact thet if the bolling of albumen and potach ba arrested $s_{i}$ fore the alkali has had time to reacr, completely upon a'l the albumen in solution, and the liquid be then cooled, no sulphide is precipitated by the addition of lead solution to the cold liquid, but on boiling again in presence of lead blackenıng is at once observed." I do not admit, and this is the point which throughout this controversy I have maintained, that under the first-named circumstances no evidence of sulphide is obtainable.

I am, Sir, your obedient servant

Grosvenor-street, Jan. 16th, 1883. F. W. PAYY.

\section{To the Editor of THE LANCET.}

Sir,-- I find by direct experiment that when potash acts upon egg albumen there is a continuous slow evolution of ammonium sulphide, until all the sulphur is expelled in the volatile form. This explains fully the behaviour of albumen both in Dr. Pavy's and Mr. S. Johnoon's experiments. If either of the gentlemen named had taken the precaution to boil the albumen in a flask connected with a suitable condensing arrangement, so as to pass the distillate into lead solution, they would have discovered this reaction. The text-books are not wholly incorrect; an alkaline sulphide is formed, but volatile, not fixed. I am. Sir, yours truly.

\section{St, Marylebone, Jan. 15th, 1883. A. WYNTER BLYTH.}

* We think this matter has now been sufficiently discussed.-ED. L.

\section{"PAUSES IN RESPIRATION."}

\section{To the Editor of THE LANCET.}

SIR,-These "pauses" occurring in a recent case of mine' and recollecting that I had read something of them in your journal a year or two ago, I referred to my assortment of old numbers, one of which (THE LANCET of October 30th, 1880), contained Dr. O'Neill's striking article, headed as above. I wish to publish in your columns if you will kindly permit me, as a corollary of Dr. O'Neill's article, a case in which the pauses were no less marked thin they were in those coming under his observation.

The patient, a middle-aged gentleman of bronzed com. plexion presented the appearance of one who had passed most of his life in India. He had suffered from Bright's disease for some years, and when he came under my care symptoms of such gravity had manifested themselves as to indicate that the end was not far off. Abundant general dropsy and albuminuria, flatulence, vomiting, pulmonary œdema, amaurosis, hypertrophy of the heart, \&c., were the distressing symptoms. To these was added what has been called Cheyne-Stokes respiration. In this, the third and most remarkable instance of its occurrence in my experience, the "series of ascending and descending respiratory acts" (to quote Dr. O'Neill's phraseology) was so marked, and the pause so prolonged, as often to excite a suspicion, until an examination of the pulse forbade it, that death had taken place. The respiratory acts increasing in force and frequency culminated in a climax, then died away in a corresponding ratio until they were lost in a pause, lasting fully a minute, profound as death. During the pause, as in Dr. O'Neill's cases, the pulse was quite strong and regular, and did not appear to me, as it did to him, to lose anything in strength to wards the end of the interval. On applying the ear to the præcordial region the heart sounds alone were heard "strangely reverberating" through the motionless walls of the chest. The eyes were shut and the mouth open, but not a twitch or wrinkle disturbed the perfect calm of the countenance. By-and-by the breathing would recommence, the eyes open, and the apparently dead man, so to speak, would again come to life. My other patients in which the panses occurred were cases of apoplexy, which I believed had affected the medulla oblongata, and in this way I accounted for the interrupted breathing. But in this case there was, so far at least as $I$ could discern, no brain Jesion to account for it, and unless the hypertrophy of the heart and pulmonary oedema, by acting injuriously on the medulla oblongata, had produced it, I can assion no other cause. Yet, if those pauses are to be explained by functional derangement of the medulla oblongata, how is it that Cheyne-Stokes reztiration is so rarely met with when cardiac disease is so common?

The Pathological Socizty of London, by directing its 